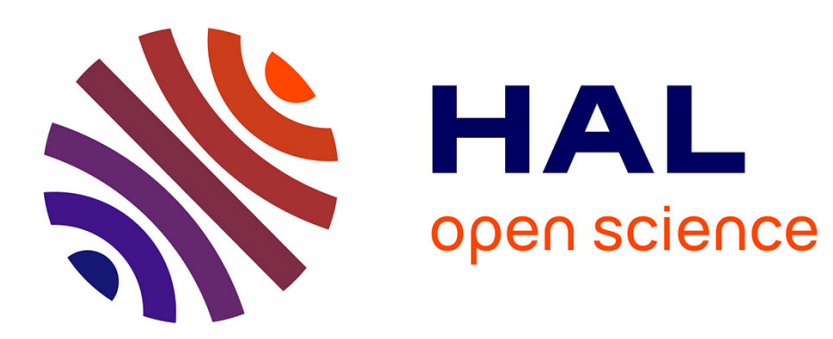

\title{
The Interaction between Presupposition and Focus: Classical Greek Wh-Exclamatives
}

\author{
Richard Faure
}

\section{To cite this version:}

Richard Faure. The Interaction between Presupposition and Focus: Classical Greek Wh-Exclamatives . Journal of Greek Linguistics, 2012, 12 (2). hal-01237018

\section{HAL Id: hal-01237018 https://hal.science/hal-01237018}

Submitted on 2 Dec 2015

HAL is a multi-disciplinary open access archive for the deposit and dissemination of scientific research documents, whether they are published or not. The documents may come from teaching and research institutions in France or abroad, or from public or private research centers.
L'archive ouverte pluridisciplinaire HAL, est destinée au dépôt et à la diffusion de documents scientifiques de niveau recherche, publiés ou non, émanant des établissements d'enseignement et de recherche français ou étrangers, des laboratoires publics ou privés. 


\title{
The Interaction between Presupposition and Focus: Classical Greek Wh-Exclamatives
}

\author{
Richard Faure \\ Université de Nice-Sophia Antipolis \\ UMR 7320 Bases, Corpus, Langage (BCL) \\ faurerichard5044@neuf.fr
}

(pre-print version, accepted for publication in Journal of Greek Linguistics, 2012, 12.2, published by Brill, http://www.brill.com/journal-greek-linguistics)

\begin{abstract}
In this paper, we argue against the claim that exclamatives could be reducible to interrogatives in Classical Greek as sometimes argued for English. Exclamatives are original in that they denote presupposed propositions, are headed by specific (wh-morpheme $h$-) and focused wh-items. They necessarily involve degrees. We try to make sense of all these features by showing that the exclamative speech act resides in the meeting of knowledge (presupposition, specificity) and unexpectedness (focus, extended scales) at the semantic/pragmatic/syntax interface.
\end{abstract}

Keywords: exclamative; exclamation; focus; presupposition; degree; ö $;$;í

\section{Introduction}

Classical Greek (henceforth $C G)^{1}$ data challenge existing theories on exclamatives. Exclamative clauses and the speech act they convey are often described with respect to the interrogatives. Indeed, across languages, wh-exclamatives often share with interrogatives a wh-term, as in English ((1)/(2)). But in CG, this is not the case. As shown below, $(3)^{2}$ (an exclamative) and (4) (an interrogative) display items belonging to different paradigms.

(1) What a (kind) boy came here yesterday!

(2) What are you doing?

\footnotetext{
${ }^{1}$ I will consider as CG Attic Greek spoken in the fifth and fourth Centuries BCE. This study was run on a corpus made of Plato's Respublica, Protagoras and Gorgias, Xenophon's Cyropaedia and Anabasis, and Demosthenes' first 21 speeches. Other authors have also been considered: Aeschylus, Aristophanes, Euripides, Isocrates, Lysias, Menandros and Sophocles. The abbreviations are those of the classical dictionary of H. G. Liddell and R. Scott ((1996) A Greek-English Lexicon. With a revised supplement, revised and augmented by H. S. Jones, with the assistance of R. McKenzie, Oxford, Clarendon Press).

${ }^{2}$ I gloss the examples according to the Leipzig glossing rules. Here are the glosses specific to Greek: AOR = aoriste (a past tense), OPT = optative (a mood). Unless mentioned, translations are taken from the Perseus website http://www.perseus.tufts.edu.
} 
(3)
Oĩov

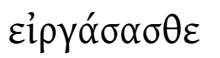

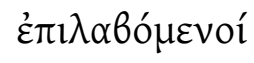

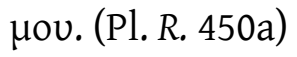
what.a-ACC.N.SG
do-IND.AOR.2PL
challenge-PTCP.AOR.NOM.M.PL
PRO-GEN.1SG

'What a thing you have done in thus challenging me!'
(4) Пог̃ov

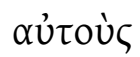
o’ $\delta i ́ k \eta \mu \alpha$

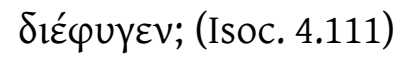
which-ACC.N.SG PRO-ACC.M.PL injustice-ACC.SG escape-IND.AOR.3SG

'What crime have they overlooked?'

This specific material is a clue that something more needs to be said about the syntax and the semantics of the two types of clauses. It will help us understand how the exclamative speech act is construed. It does not reside in a specific illocutionary operator but is rather the compositional effect of several features: presupposition, focus and extended degree scale. The main contribution of my article is to highlight the central role of focus, very little discussed in previous works.

The paper is organized as follows: in section 2, I present CG wh-exclamatives. In section 3, I argue that they denote presupposed propositions. In section 4 , I show that the focus plays a crucial role in their semantics. In section 5, I combine the previous results with the degree present in every CG wh-exclamative and show how the exclamative speech act is derived.

\section{Classical Greek data}

CG exclamatives display several peculiarities. First, the heading term is explicitly a degree term; second, the wh-morpheme used in exclamatives is not the same as that used in interrogatives. It has a specific semantics. Finally, there seems to be a one-to-one correspondence between direct and embedded exclamatives which allows us to carry over to the former the points made on the latter. I shall address these points in turn.

\subsection{Wh-exclamative items are terms of degree}

In CG wh-exclamatives, only four items can be used: oíos 'what a' (5), öøos 'how much/many' (6), ì $\lambda$ íkos 'how much/many' (7) and ís 'how' (8).

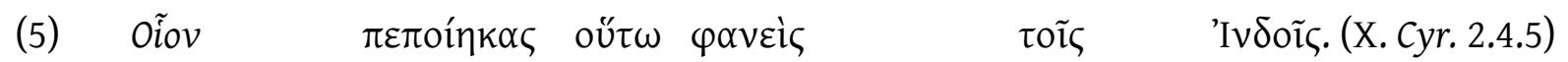
what.a-ACC.N.SG do-IND.PRF.2SG thus appear-PTCP.NOM.M.SG ART-DAT.M.PL Indian-DAT.PL

'What a thing you have done thus appearing before the Indians!' (my translation)

\begin{tabular}{|c|c|c|}
\hline 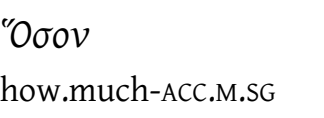 & 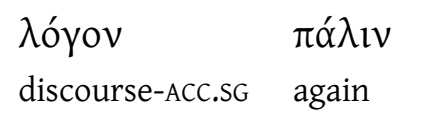 & 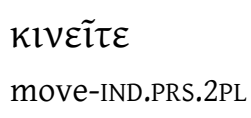 \\
\hline & 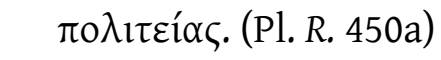 & \\
\hline ART-GEN.F.SG & polity-GEN.SG & \\
\hline
\end{tabular}

'What a huge debate you have started afresh about this polity!' 


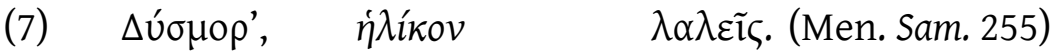

poor-VOC how.much-ACC.N.SG talk-IND.PRS.2SG

'Unlucky you, how you prattle on!' (my translation)

$(8)$

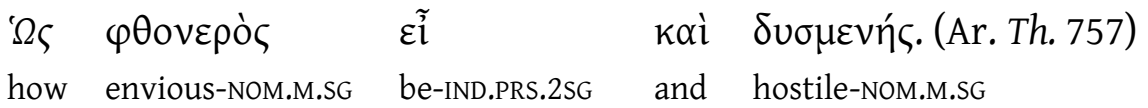

'You pitiless monster!'

They are morphologically composed as such:

h-ỗ-os

h-ó $\sigma-o \varsigma$

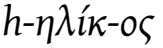

$h-\omega(\varsigma)$

As is obvious, they all share the wh-morpheme $h$-, presented in the next section. -os in the

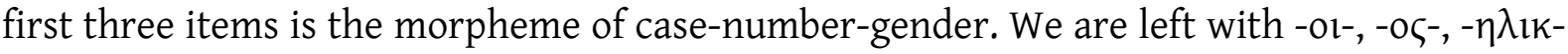

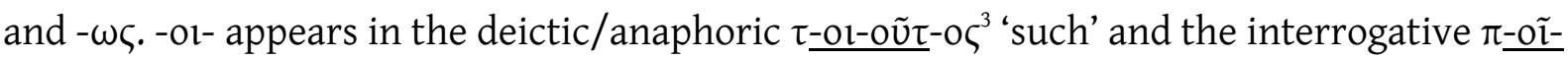

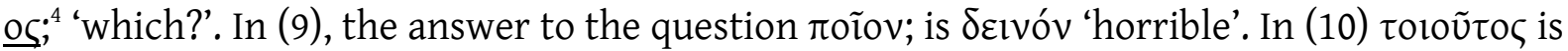
anaphoric to $\psi \varepsilon v \delta \eta ́$ ' 'false'. This means that -ol- stands for a noun modifier, especially for a gradable adjective $e^{5}$.

(9)

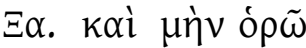

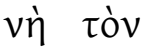
$\Delta$ l. $\pi$ oíóv $\quad \tau$;
which-ACC.N.SG INDF-ACC.N.SG
$\Xi \alpha$.
Selvóv. (Ar. Ra. 288-289)
horrible-ACC.N.SG

Sía $\quad$ Onpíov

$\mu \varepsilon ́ \gamma \alpha$.

PTC PTC see-IND.PRS.1SG PTC ART-ACC.M.SG Zeus-ACC monster-ACC.SG big-ACC.N.SG

'Xanthias. And now, by Zeus, I see a monstrous beast.

Dionysus. What kind?

Xanthias. O horrible!'

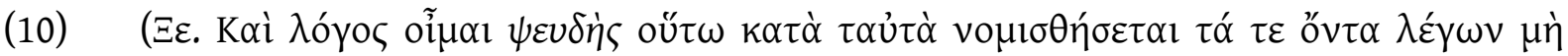

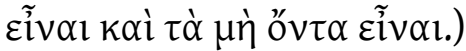

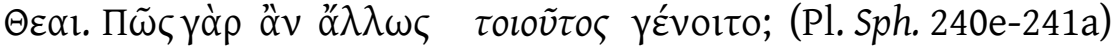
how PTC PTC otherwise such become-OPT.AOR.3sG

'(Stranger. And therefore a statement will likewise be considered false, if it declares that things which are, are not, or that things which are not, are.)

\footnotetext{
${ }^{3} \tau$ - is the morpheme elsewhere found in the definite article; -ov $\tau$-o $\zeta$ is the medial/neutral demonstrative.

${ }^{4} \pi$ - is the interrogative wh-morpheme. $\tau(\mathrm{l})$ - in an allomorph found in $\tau$ 'í ' 'who' etc.

${ }^{5}$ The other possibilities include at least relational adjectives (E. Rh. 278-279) and NPs in the genitive (A. A. 1087-8).
} 
Theaetetus. In what other way could a statement be made false?'

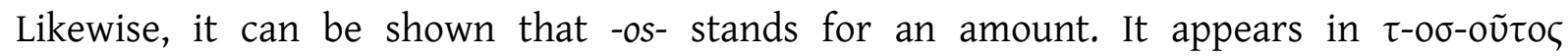

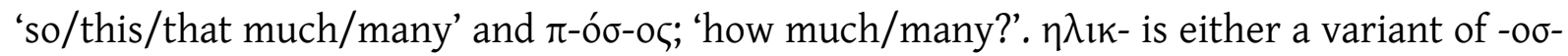
or relates more specifically to age ( $\left.\tau-\eta \lambda_{\imath \kappa}-o \tilde{v} \tau-o \varsigma, \pi-\eta \lambda \lambda^{\prime} \kappa-o \varsigma\right)$. Finally, - $\omega \varsigma$ denotes the manner as in oü $\tau-\omega(\varsigma)$ 'thus' and $\pi-\tilde{\omega} \zeta$; 'how?'. But $\omega \varsigma$ denotes the degree when it bears on gradable adjectives, gradable adverbs or on verbs, in which case one can supplement it with a fuzzy adverbial like 'much' ${ }^{6}$. This means that all $C G$ wh-exclamatives explicitly range among gradable, i.e. degree expressions.

This has been previously argued for French by Milner 1978, for Catalan by Castroviejo Miró 2007 and for English by Rett 2009, 2011. Even when there is no overt degree morphology, only the degree interpretation is available 7 . This is shown for example in Rett 2009 for (11). (11) cannot be uttered to say that it is impressive that Mimi speaks Javanese and Tagalog (individual reading). It can only be uttered to say that it is impressive that Mimi speaks languages that have such and such characteristics, say, that are so exotic.

What languages Mimi speaks!

The degree denotation is also shown by the necessity to use a sentential exclamative if we are dealing not with gradable, but with relational properties. (12) with a relational property and an unambiguous wh-exclamative is discarded. A sentential exclamative (13) must be used instead. On the other hand, in (14) a gradable property (length) is available for a whexclamative.

(12) \#A. This plane is the president's.

B. What a plane it is!

(13) A.This plane is the president's.

B. (This plane is) the president's!

\footnotetext{
${ }^{6}$ This is the case in (32), literally 'how much you rightly-think'.

${ }^{7}$ Many languages have who-exclamatives. Rett (2008:footnote 3) argues that despite the absence of overt degree morphology, these exclamatives also have a degree interpretation (roughly, "Who I met" in these languages means "What wonderful people I met"). D'Avis $(2001,2002)$ builds most of his theory on wer (=who)exclamatives in German, but Abels (2004:footnote 4) casts doubt on such sentences: they may be "rhetorical" questions, thus indirect speech acts and not exclamatives per se. Finally, Chernilovskaya and Nouwen (to appear) point out that this is not the case for Dutch: wie (=who)-exclamatives have a specific syntax and do not have a degree interpretation. They conclude from this fact that degrees are not universally present in whexclamatives and that something else, more encompassing, must be found, such as their noteworthiness notion. Nonetheless, they cannot dispense with scalarity. As I am here mainly concerned with Classical Greek, a language that always displays gradable predicates and/or overt degree morphology, I will stick to the idea that degree is always involved, at least in this language.
} 
(14)
A.This plane is $500 \mathrm{~m}$ long.
B. What a plane it is!

In CG, only wh-exclamatives in oĩos are available to express sentences like (14). I shall come back to the question of why this is so in section 5 .

2.2 Wh- items: the wh-morpheme h-

Another common point of the four wh-items used in wh-exclamatives is that the whmorpheme takes the form of $h$-. This section is devoted to highlighting the meaning of $h$-, especially with respect to the other wh-morpheme available $\tau(1) / \pi$ - which is used in interrogatives. We shall learn several differences between exclamatives and interrogatives. The morpheme $h$-is also present in $h$-óc. "O $\zeta$ is a polyfunctional wh-item. It is used in:

- Restrictive relatives (15),

- Free relatives (16),

- Embedded interrogatives (17).

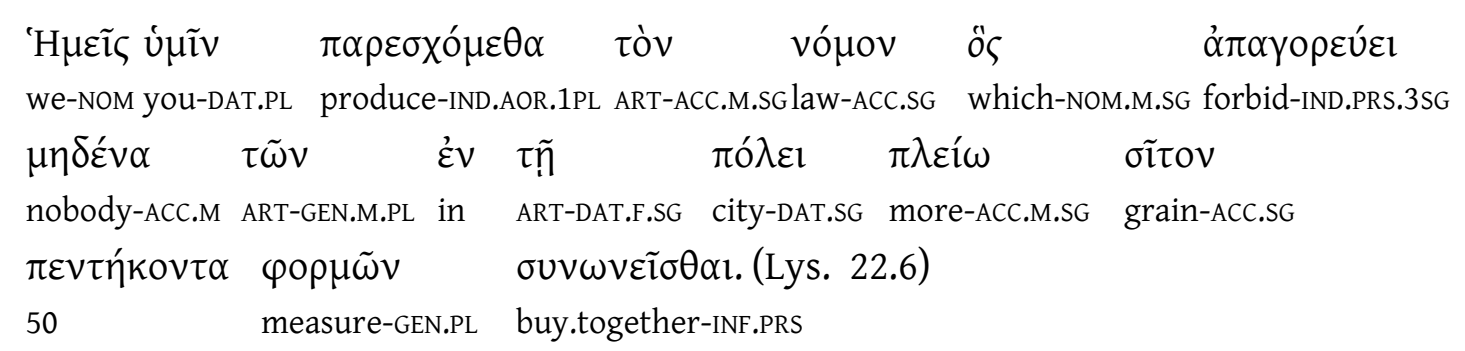

'For we have produced to you the law which forbids anyone in the city to buy up corn in excess of fifty measures.'

\begin{tabular}{|c|c|c|}
\hline$\pi \alpha \rho \alpha \delta \circ \tilde{v} v \alpha l$ & $\delta i \grave{~}$ & 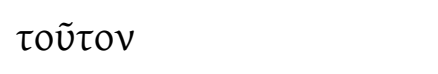 \\
\hline hand.over-IND.AOR & who-NOM.M.SG because.of & DEM-ACC.M.SG \\
\hline 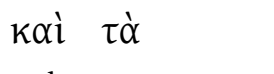 & $\dot{\alpha} \mu \alpha \rho \tau \eta \dot{\mu} \mu \alpha \tau c$ & $\chi \quad \dot{\alpha} \pi \varepsilon \varepsilon_{\theta} \alpha v \varepsilon v$. (Lys. 6.22) \\
\hline and ART-ACC.N.PL & DEM-GEN.M.SG offence-ACC.PL & die-IND.AOR.3SG \\
\hline
\end{tabular}

'to hand over (the man) who had been put to death in order to shield this man and his offences' (Perseus modified)

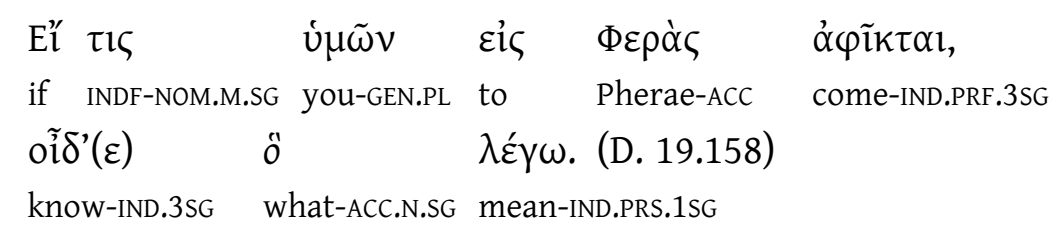

'Any of you who have been to Pherae will know what I mean' (Perseus modified) 
Despite this variety of usages, ǒ s semantics is reducible to one main feature. As a matter of fact, its distribution is limited to some cases. I sketch here an analysis present in much more detail in Faure 2010.

(15) displays a restrictive relative clause with a definite antecedent. In the other configurations (non restrictive/appositive relatives, relatives with an indefinite antecedent and free relatives), other items (like ö $\tau \iota \varsigma^{8}$ ) can show up as well and the distribution between ö and ö $\tau 1 \varsigma$ hinges on other factors (cf. below). But in the case of (15), only ö is used in the corpus. This is the only case where we grasp all and only the individuals sharing the two properties of being a law and forbidding buying too much corn. The maximality entails the complete overlap, the perfect identification between two subsets. This is not the case with an indefinite expression like two cats that are black where we do not pick up all the black cats.

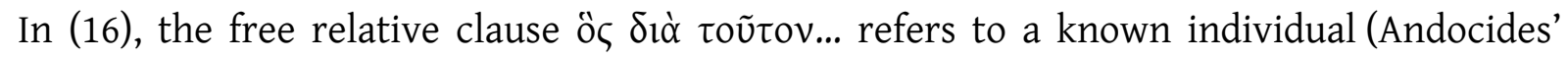
slave). Only ös can show up in such free relatives. On the other hand, in generic or non

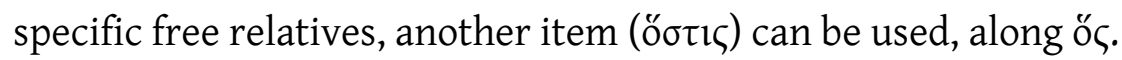

In (17), the ö $\zeta$-clause must be interpreted as an embedded interrogative. In the first place, the hallmark of free relatives, i.e. the conjunction of the selection between the matrix and the embedded verb, is not met (Eriksson 1982). Moreover, the clause denotes a proposition ('what I mean' = 'that there is an inn in front of the Dioscuri's temple') and not an individual ('what I mean' $\neq$ 'the thing I'm thinking of'). Finally, (17) forms a pair with (18) and (19),

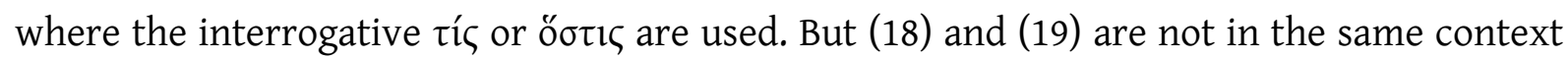

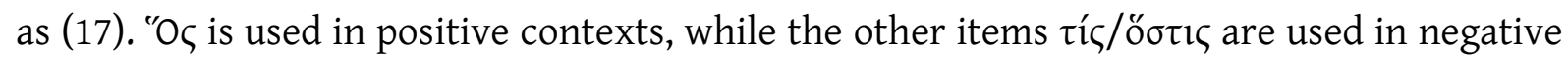
ones. As a matter of fact, negative contexts extend to nonveridical contexts as defined in Zwarts $1995(20)^{9}$.

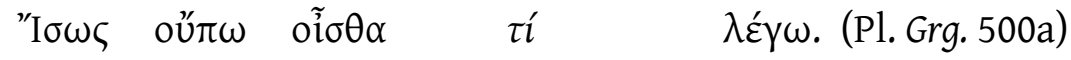

$$
\begin{aligned}
& \text { maybe not.yet know-IND.2sG what-ACC.NT mean-IND.PRS.1SG }
\end{aligned}
$$

'You may not know yet what I mean.'

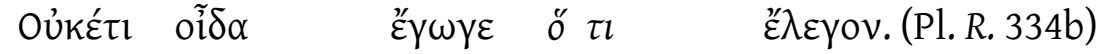

$$
\begin{aligned}
& \text { no.longer know-IND.1sG I.myself what-ACC.N.SG mean-IND.PRET.1SG }
\end{aligned}
$$

'I no longer know what I did mean.'

\footnotetext{
${ }^{8}$ Morphologically, ö $\sigma ı \varsigma$ is composed of ö and the indefinite $\tau \iota \varsigma$, but the morpheme $h$ - is not active in this item, maybe under the influence of the indefinite.

${ }^{9}$ Note that this is also the case in thetic sentences: there is something that (ö $\left.\zeta\right)$ (cf. Lys.22.6), there is no one

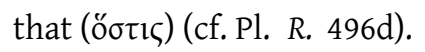


(20) Nonveridical operators

Let $O$ be a monadic sentential operator. $O$ is said to be veridical just in case $O p \Rightarrow p$ is logically valid. If $O$ is not veridical, then $O$ is nonveridical.

Moreover, ö $\zeta$-clauses are limited to cognitive predicates like oĩ $\delta \alpha$ 'know'10, whereas

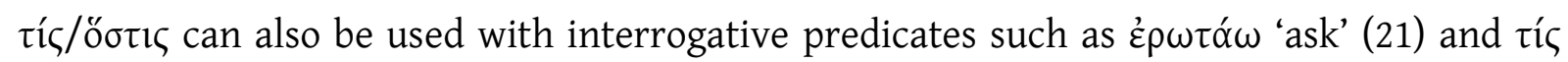
even appears in direct questions (22). This suggests that ö -clauses are restricted to contexts where the true answer is known by the speaker or at least by the subject of the matrix verb and that they denote the true answer to the question rather than the question itself (as shown for wh-clauses with know by Groenendijk \& Stokhof 1984).

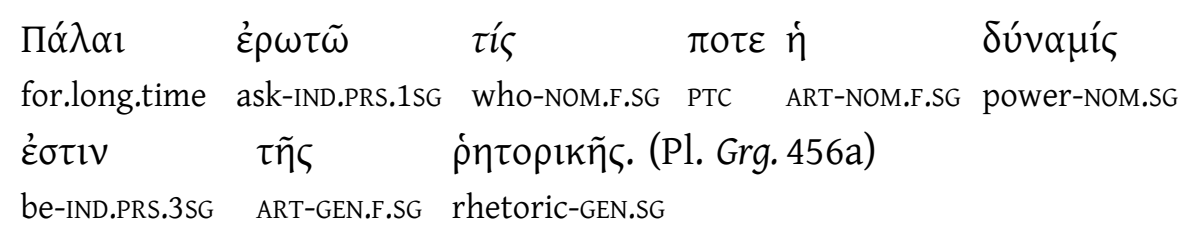

'This has made me ask you all this time what in the world the power of rhetoric can be.'

$$
\begin{array}{ll}
\text { Tís } & \alpha U ̋ \tau \eta ;(P l . P h l b .16 b) \\
\text { what-NOM.F.SG } & \text { DEM-NOM.F.SG }
\end{array}
$$

'What is the road?'

To sum up, ǒ can be used only when identification, specificity or definiteness are at stake:

- In restrictive relatives with definite antecedent where maximality implies identification between two subsets,

- In referential, specific free relatives,

- In embedded interrogatives that denotes the true answer to a question.

As ó bears the morpheme $h$-, the identification property must be attributed to it. From the first condition (see the previous section) that an exclamative must explicitly involve degree, ös cannot show up in exclamatives. Nevertheless, we are left with the conclusion that identification is somehow involved in the characterization of exclamatives. Moreover, the morpheme $h$-is mostly used in relative terms ${ }^{11}$. The idea that exclamatives may be cognate to relatives and especially to free relatives has already been raised in Zanuttini \& Portner (2003:62) and in Rett 2009 (on Hebrew data). Note nevertheless the restrictions on this connection dating back to Elliott (1974:236-7): free relatives denote properties or individuals, exclamatives denote propositions (see section 3). This issue is solved if we

\footnotetext{
${ }^{10}$ More on this point below in 2.3 and 3.2.2.2.

${ }^{11}$ The case in point is the use as embedded interrogative. Faure 2009 proposes that ö $\zeta$-clauses be uniformly treated as relatives and that the so-called embedded interrogatives are in fact free relatives used as concealed questions.
} 
consider that the morpheme $h$ - does not have the same usage in the two clause types. In the exclamatives, it does not bind an individual variable at the end of the derivation (yielding an individual), but the degree variable before the end of the derivation, the individual variable being bound by existential closure, thus yielding a proposition, as desired. For an example see below (73).

If I am right, this means that exclamatives cannot be on a par with interrogatives, something already drawn from the morphology in introduction. This has important consequences for some of the most influential theories on exclamatives such as d'Avis 2001, 2002 or Zanuttini \& Portner 2003 that both claim that exclamatives are interrogatives i.e. denote sets of propositions (according to Karttunen's 1977 theory). This claim is crucial in that it elicits the treatment of exclamatives as a widening of a set (Zanuttini \& Portner) or as alternatives to a norm proposition (d'Avis). It does not seem to be tenable for CG data (an account of where the exclamatives-as-interrogatives idea comes from is given in 5.3). The exact correspondence between indirect and root exclamatives suggests that exclamatives denote propositions rather than sets of propositions, since they are embedded under propositional attitude verbs. I address this point in the next section.

\subsection{Direct and indirect exclamatives}

The claim that exclamatives are embeddable is not uncontroversial. The suspicion arose because of the mismatch in English between what is interpreted as an exclamative in direct and in indirect environments. Rett 2011 correctly notes that direct exclamatives in who do not exist but that a predicate like surprise does embed such sentences (24) with a meaning similar to what one could expect (23) to mean.

(23) *Who came to the party yesterday!

(24) Patricia was surprised by who came to the party yesterday.

Along the same lines, surprise embeds multiple wh-exclamatives, which are not possible as direct exclamatives: (26) (borrowed from Rett) is felicitous, but not (25).

(25) *Who ate what!

(26) I'm surprised at/by who ate what.

Moreover, direct exclamatives necessarily have a degree interpretation (recall example (11)) while wh-clauses under surprise do have an individual reading. Apparently, (27) is felicitous when Mimi speaks Javanese and Tagalog and when it is this fact that surprises me.

(27) I am surprised at/by what languages Mimi speaks. 
Finally, a sentence is claimed to convey only one speech act and (24), (26) and (27) are definitely assertions and not exclamations.

None of these arguments holds for CG. First, the items used in embedded exclamatives are

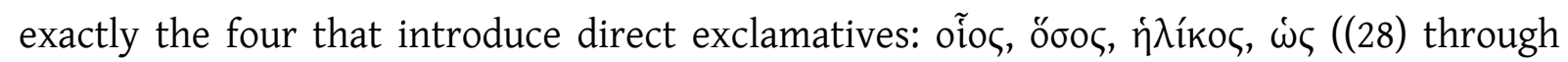
(31)). Given that they are degree expressions, exclamatives have the same degree interpretation, be they direct or embedded. The individual interpretation never arises.

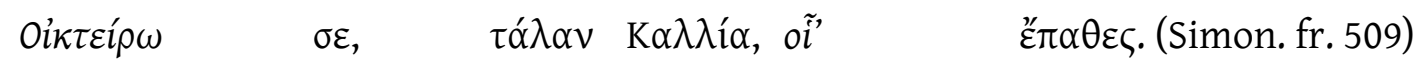

$$
\begin{aligned}
& \text { be.sorry-IND.PRS.1SG PRO-ACC.2SG poor-VOC K-VOC what.a-ACC.N.PL suffer-IND.AOR.2SG }
\end{aligned}
$$

'I am sorry, poor Callias, for what you suffered.' (my translation)

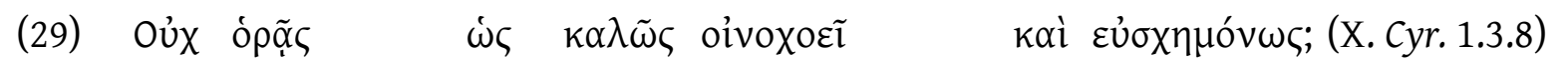
NEG see-IND.PRS.2SG how nicely pour.vine-IND.PRS.3sG and gracefully

'Do you not see how nicely and gracefully he pours the wine?'

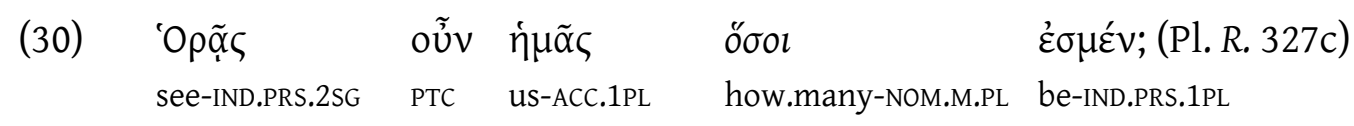

'But do you see how many we are?'

$$
\begin{aligned}
& \text {... ó } \rho \tilde{\omega} v \quad \dot{\eta} \lambda i ́ k o s \quad \eta ̋ \delta \\
& \text { see-PTCP.NOM.M.SG how.much-NOM.M.SG already }
\end{aligned}
$$

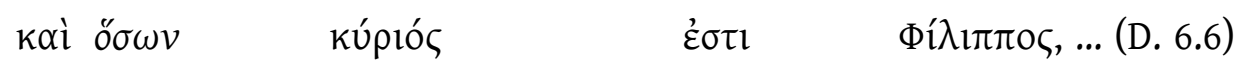

$$
\begin{aligned}
& \text { and how.many-GEN having.power-NOM.M.SG be-IND.PRS.3SG P-NOM }
\end{aligned}
$$

'if anyone views with confidence the present power of Philip and the extent of his dominions,...'

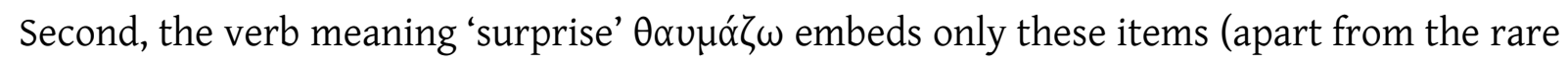
ìí́kos).

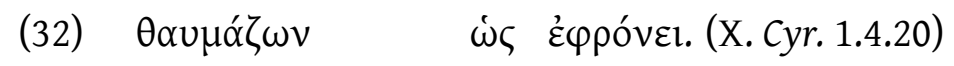

wonder-PTCP.NOM.M.SG how be.shrewd-IND.PRET.3SG

'Wondering how shrewd the boy was.' (my translation)

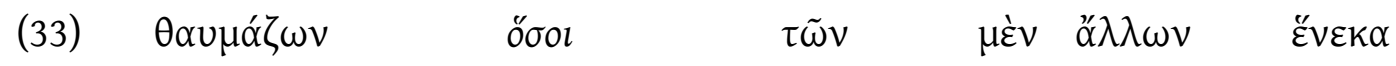
wonder-PTCP.NOM.M.SG how.many-NOM.M ART-GEN.N.PL PTC other-GEN.N.PL for

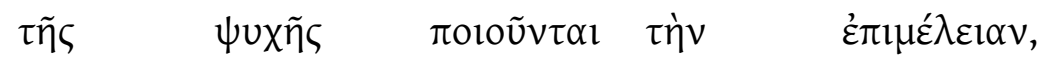
ART-GEN.F.SG mind-GEN.SG do-IND.PRS.3PL ART-ACC.F.SG care-ACC.SG

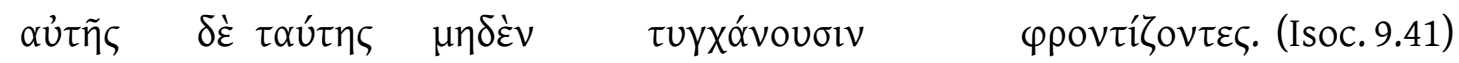
PRO-GEN.F.SG PTC DEM-GEN.F.SG nothing-ACC.N happen.to.be-IND.PRS.3PL take.care.of-PTCP.NOM.M.PL


'And he marveled at how many people, while they cultivate the mind for all other ends, take no thought of the mind itself.' (Perseus modified)

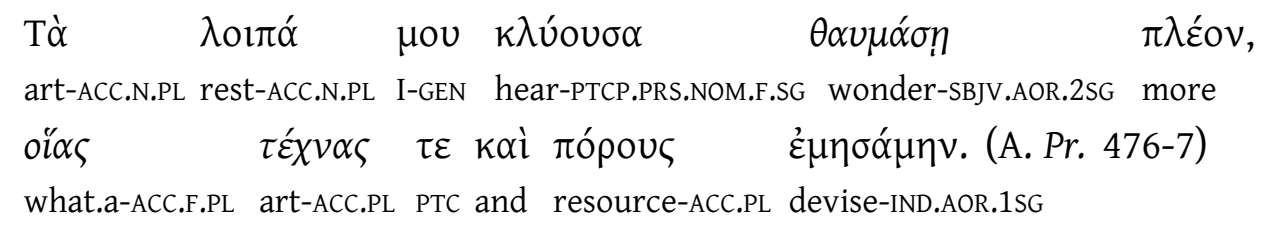

'Hear the rest and you shall wonder the more at the arts and resources I devised.'

Otherwise, with items of the $\tau$ íc/interrogative paradigm, it changes its meaning from 'surprise' to 'ask with surprise', i.e. it becomes a real interrogative verb (35), much as 'wonder = marvel' and 'wonder = ask oneself'.

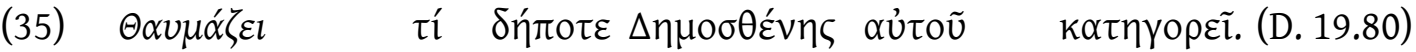
wonder-IND.PRS.3SG why PTC D-NOM PRO-GEN.M.SG accuse-IND.PRS.3SG

'He will wonder why his accuser is Demosthenes.'

Third, there are embedded multiple exclamatives (36) and this is the result of the embedding of direct multiple exclamatives (37). Note that in these exclamatives each wh-items bears on a different predicate. The conjunction of the two makes the situation unexpected.

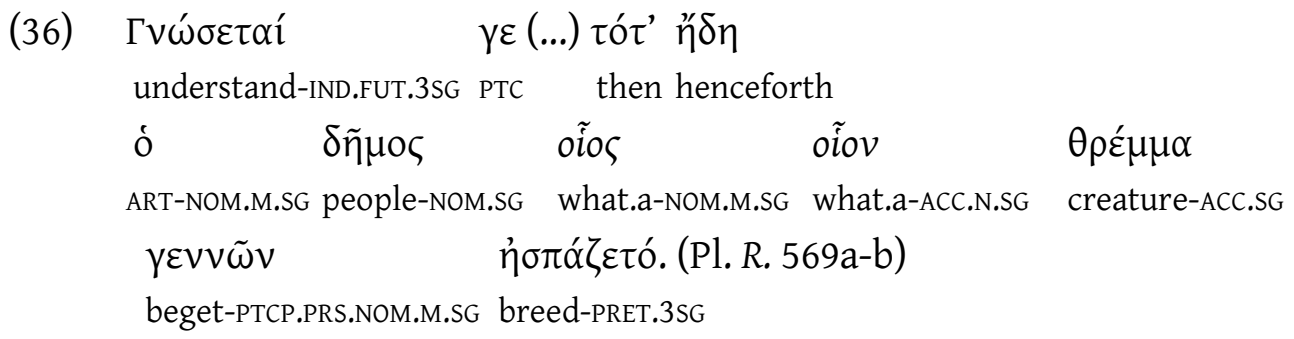

'The demos will then learn what it is and what a creature it begot.'

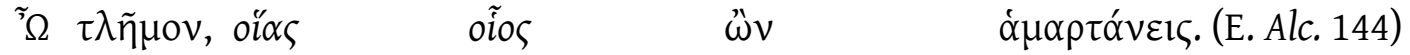

$$
\begin{aligned}
& \text { PTC poor-voc what.a-ACC.F.PL what.a-NOM.M.SG be-PTCP.NOM.M.SG lose-IND.PRS.2SG }
\end{aligned}
$$

'Unhappy man, being so good a husband, to lose so good a wife!'

The last point raised by Rett is that of the speech act. The embedding predicate spells out

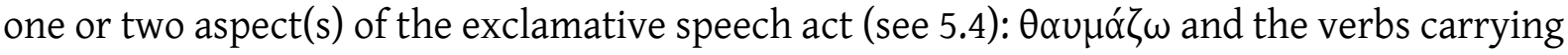
a focusing operator (see for example (29)/(30)) spell out the focus/unexpectedness dimension; cognitive factive predicates encode the presupposition; emotive factive verbs encode both. This means that part or totality of what constitutes the exclamative speech act is carried out by an operator of the matrix clause. But this operator licenses a feature of the embedded clause and do not substitute for it. If I am right in positing a straightforward 
equivalence between direct and indirect exclamatives, we should be able to draw conclusions for wh-exclamatives in general from the observation of one or the other. As exclamatives are embedded under attitude verbs, they must denote propositions.

\subsection{Wrap up}

In this section, we learned that $C G$ wh-exclamatives range among degree terms, that they are somehow identificational and that embedded exclamatives do exist and have exactly the same properties as root exclamatives. Both denote propositions. In the following sections, I am going to explain what it means for a clause to be headed by an identificational term, what the parallel between embedded and root exclamatives tells us and what role degrees play.

\section{Exclamatives as presupposed propositions}

That something in exclamative clauses is taken for granted is widely accepted since the seminal works on exclamation in the 1970s of Elliott 1974 and Grimshaw 1979, be it called factivity (Zanuttini \& Portner 2003), presupposition (Abels 2010) or implicature. Abels 2010 and Rett 2011 cast doubt on several tests that are supposed to show this factive feature, but Abels finally proposes a new argument in favor of it, while Rett discards the factivity. I shall follow Abels and take up the problem anew first on English data before going back to CG, especially concerning embedding verbs. But it should be recalled first that exclamatives denote propositions, as shown in 2.2 .

\subsection{Previous discussions ${ }^{12}$}

\subsubsection{Embedding under factive verbs}

The first point to be discussed is the embedding of exclamatives by factive verbs, e.g. know in (38). Given that factive verbs are attitude verbs and that they are presuppositional, exclamatives are taken to denote presupposed propositions. But there are several objections to this claim. First, there is not an exact correspondence between so-called embedded exclamatives and direct exclamatives in English (see section 2.3). We therefore cannot carry over a conclusion drawn from embedded clauses to direct exclamatives. Second, if exclamatives are presuppositional, they should keep their presupposition under other predicates, which is not necessary. As highlighted by Abels 2010, this is only explained under Kiparsky \& Kiparsky's 1970 discutable view that non-factive operators are antifactive. Otherwise, the presupposition might be conveyed by the factive verb and not by the clause. As there are many biased arguments on both sides, I shall go back to this issue below and discard this test for the moment.

\footnotetext{
${ }^{12}$ The reader would find a good, though somewhat different, account of the following points in Abels 2010.
} 
(38) Peter knows what a success Michael had.

(39) Peter knows/does not know that Michael had a lot of success. $\rightarrow$ Michael had a lot of success.

\subsubsection{Incapacity to answer a question}

The second point is that a presupposed proposition does not convey anything new and that it should therefore be unable to answer a question, which is borne out for exclamatives: (40). But, it can also be explained pragmatically: the exclamation is not the right speech act to answer a question (Rett 2011). This is probably a better account, given that we have some clue that there might be something asserted in exclamatives (see below the comment on examples (45) and (46)).

(40) Question: How tall is John?

Answer: Very tall.

Answer: \#How tall John is!

\subsubsection{Hey, wait a minute and Not really tests}

A third point is made up by the Hey, wait a minute! test, made popular by von Fintel 2004. Hey, wait a minute! marks the reaction of the hearer when she does not endorse the presupposition of the speaker's utterance. (41) ((41), (42), (45) (except B'), (46) and (47) are from Rett 2008:198-200) shows that Hey, wait a minute! does not discard the asserted part (does macramé), but can discard the presupposed part (that Mico is married). But the part of the exclamative one exclaims on cannot be discarded this way (42).

(41) A: Mico's wife does macramé.

B: Hey, wait a minute! Mico's not married.

B': \#Hey, wait a minute, she doesn't do macramé!

(42) A: What incredibly large feet you have!

B: \#Hey, wait a minute, they're not that big!

Actually, (44), the French version of (42), sounds totally acceptable to me (note that the test otherwise works for French, see (43), which translates (41)). This means either that the test is misleading for exclamatives ${ }^{13,14}$ or that exclamatives have at least a presupposed part.

\footnotetext{
${ }^{13}$ Much more on the weakness of this test in Abels (2010:148-150).

${ }^{14}$ An anonymous reviewer points out to me that the hey, wait a minute test is even more confusing, for it seems to also identify conventional implicatures, which would mean that it is a test for general assertorically inert material. I do not need to go into these details here.
} 
(43) A: La femme de Mico fait du macramé.

B: Non, mais attends ! Mico n'est pas marié.

B': \#Non, mais attends! elle ne fait pas de macramé !

(44) A: Quels pieds gigantesques!

B: Non, mais attends ! Ils ne sont pas si grands que ça !

On the other hand, the Not really test discards the asserted part of the utterance. In (45) it is felicitously used only to discard that Mico's wife does macramé and not that Mico is married. This test has some effect on exclamatives as shown by (46), which would mean that exclamatives have some asserted part. A word of caution is in order here, however, for Abels 2010 notices that the Not really test does not always fail on presupposition. In (47), it discards the presupposition that Sue smoked.

(45) A: Mico's wife does macramé.

B: \#Not really; he's not married.

B': Not really; she rather hand-knits.

(46) A: How very tall Elwood is!

B: Not really; he's just wearing platform shoes.

(47) A: Sue stopped smoking.

B: Not really. She never smoked.

The embedding and the rejoinder tests leave us with a confused picture. The next section is an attempt to disentangle it.

\subsection{Rescuing the presupposition}

3.2.1 English exclamatives: sensitivity to plugs, holes and filters

Abels 2010 points out that those tests are not conclusive. He goes a step further and applies to exclamatives Karttunen's 1973 tests for presuppositions. In Karttunen's theory, there are three environments for presupposed expressions: holes, where the presupposition is projected (e.g. negation); plugs where it is prevented from projecting (e.g. tell); filters where the presupposition projects but only locally (as shown later, see for example van der Sandt 1992) (e.g. conditionals). Abels claims that exclamatives behave the same way as run-of-themill presuppositions. In (48) with a hole (negation), the presupposition projects. Indeed, it cannot be denied as shown by the infelicitous follow-up. (49) is an example of a plug (the verb tell), the presupposition does not project and it can be denied by a follow-up. Finally, and crucially, in (50) (Abels' 23a), the exclamative in the scope of tell does not project. A weakness of this test is that there is no way to come up with a case where an exclamative would be in the scope of a hole. 
(48) Fred didn't stop drinking, (\#but he has never drunk). $\rightarrow$ Fred used to drink.

(49) Friends often tell me that Fred stopped drinking, but he has never drunk. / $\rightarrow$ Fred used to drink.

(50) Friends often tell me what a wonderful cook I am - I always tell them it is the ingredients, not my skill as a cook. / $\rightarrow$ I am a wonderful cook

The second part of Abels' proof is that exclamatives pattern with presuppositions and not with conventional implicatures, something that could have been expected, given the exclamatives' evaluative/emotional content, a feature attributed to conventional implicatures by Potts 2005. Appositive NPs are well-known conventional implicatures. They are not sensitive to plugs as presuppositions are. (51) contains the appositive NP a confirmed psychopath and entails the truth of the proposition that Chuck is a confirmed psychopath. When embedded under a plug for presupposition like say in (52), the truth of this proposition survives, contrary to the presupposition in $(50)^{15}$.

(51) Chuck, a confirmed psychopath, is fit to watch the kids.

(52) Sheila says that Chuck, a confirmed psychopath, is fit to watch the kids.

On the basis of this test, English exclamatives are presupposed propositions. It does not carry over to $C G$, for we are not able to build such tests on a corpus study. We can assume that $C G$ passes at least some of the previous tests. However and fortunately, we have other clues, among which are the morpheme $h$ - and the embedded exclamatives.

\subsubsection{CG exclamatives: morpheme $h$ - and embedded exclamatives}

CG exclamatives display more clues that help us characterize them as presupposed propositions. The first one is the identificational feature of the wh-morpheme $h$-, the second one is the one-to-one correspondence between direct and embedded exclamatives.

\subsubsection{Morpheme h-}

Recall that the wh-morpheme $h$ - is used when identification is possible. Depending on the situation, the morpheme $h$ - has several roles and identification is an encompassing term for specificity, definiteness etc. What is its role in the case of exclamatives? If we go back to

\footnotetext{
${ }^{15}$ As pointed out to me by an anonymous reviewer, things may be more intricate. The conventional implicature globally projects only in a speaker oriented (de re) reading (as opposed to a subject of the matrix verb de dicto oriented reading). It remains that there are cases where conventional implicatures bypass the plugs for presuppositions. This issue is addressed by Saebø 2011 who defends a view that ultimately amounts to challenging the conventional implicature status of nominal appositives. Discussing this matter would take us too far away from our topic.
} 


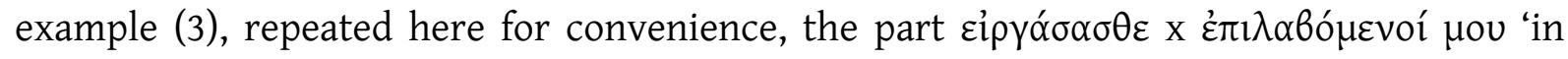
challenging me you did x' has been added to the common ground and is thus presupposed.

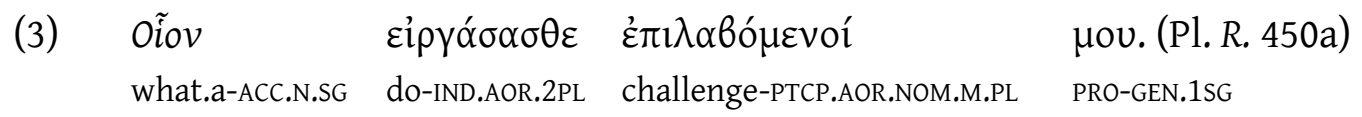

'What a thing you have done in thus challenging me!'

But it is also the case for the variable part $\mathrm{x}$ of the proposition. The $\mathrm{x}$ corresponds to oíov i.e. to a certain thing that has a certain property to a certain extent (recall section 2.1). What this thing is, what this property is and what degree on the scale of this property this thing attains is known by every participant in the discourse situation. That is why the morpheme $h$ - is used and not the other wh-morpheme $\tau(\mathrm{l}) / \pi$ - (which means that someone is missing the information). This is in line with the fact that exclamative DPs are usually definite in English as well as in CG. In addition, in CG, the DP is in the genitive case (53). To be honest, there are very few examples without a definite article, though they might have a definite interpretation (54).

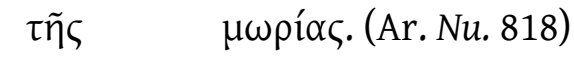

$$
\begin{aligned}
& \text { ART-GEN.F.SG folly-GEN.SG }
\end{aligned}
$$

'What folly!'

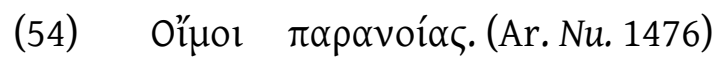

PTC madness-GEN.SG

'Ah me, what madness!'

Rett 2011 notes that exclamative DPs are usually definite, but confesses that her account provides no explanation for it. In my account, the definite article would basically play the same role as the morpheme $h$ - and bind the degree of a (possibly contextually recoverable) property.

Coming back to (3), the proposition as a whole belongs then to the common ground and (3) is tantamount to you did something very embarrassing in thus challenging me. However, what degree the embarrassment attains is not spelt out and this is the main contribution of the exclamative: saying that some degree known by everyone is attained and not being able to spell it out. I shall return later to this claim, which is for the moment informal. Suffice it for now to point out that the proposition denoted by the wh-exclamative is added to the common ground.

\subsubsection{Embedded exclamatives and embedded interrogatives}

Let us turn now to exclamative embedders. In section 2.3, we saw that CG provides a straightforward correspondence between direct and indirect exclamatives. In section 3.1.1, 
we saw that exclamatives are embedded under factive verbs. There was a suspicion that their presupposed flavor comes from the embedding verb. Here I show that exclamatives are embedded under factive verbs because they are intrinsically presupposed, contrary to that-clauses whose interpretation depends on the embedder (the proposition they denote is presupposed under know, but not under believe).

As for English (Elliott 1974, Grimshaw 1979), CG wh-exclamatives are not embedded under interrogative verbs such as $\varepsilon \rho \omega \tau \alpha$ ' $\omega$ 'ask'. They share this property with ö $\varsigma$-clauses. Recall from section 2.2, that ö -clauses with cognitive verbs denote the true answer to the question (the crucial examples are (17), (18) and (19)). But there is not a complete overlap between predicates that embed ó $\varsigma$-clauses and predicates that embed exclamatives. "O $\varsigma$ clauses denoting the true answer to a question are embedded under cognitive factive predicates (oĩ $\delta \alpha$ 'know' (17), $\mu \alpha v \theta \alpha \alpha v \omega$ 'understand' etc.) and under veridical predicates

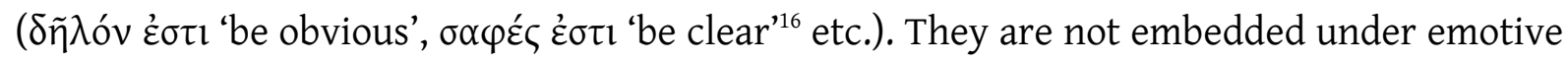
factive predicates. On the contrary, wh-exclamatives are embedded under cognitive AND

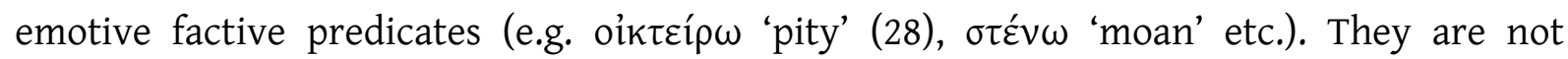
embedded under veridical predicates ${ }^{17}$. This has two major consequences.

The first consequence is that if wh-exclamatives in CG (and arguably in many languages) are licensed only after factive predicates, one can infer that they convey a factive feature ${ }^{18}$, due to the conjunction of the presupposed part of the proposition and the use of a specific whmorpheme: $h$-. If this proposal is correct, there is no need of a factive operator as argued in Zanuttini \& Portner 2003. This factive feature is a presupposition, if we follow Abels 2010 and wh-exclamatives denote presupposed propositions. Alternatively, Castroviejo Miró 2007

\footnotetext{
${ }^{16}$ Contrary to factive predicates, veridical predicates entail the truth of their complement only when not embedded under a nonveridical operator (see (20) for a formal definition). $\Delta \tilde{\eta} \lambda o ́ v ~ \varepsilon \dot{\sigma} \tau \imath$ is such a predicate:

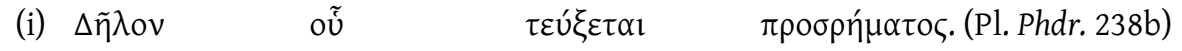

clear-ACC.N.SG what-GEN.N.SG get-IND.FUT.3SG name-GEN.SG

'We know for sure what name he (the man who drinks too much) will get.'(my translation)

${ }^{17}$ An anonymous reviewer points out (i) to me as a potential exclamative example.

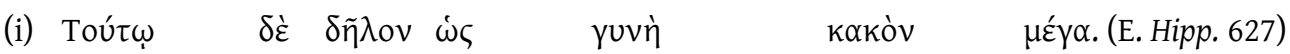

DEM-DAT.N.SG ptc clear how/COMP woman-NOM.SG evil-NOM.N.SG great-NOM.N.SG

'It's clear how great an evil woman is.' (the reviewer's translation)/'The clear proof that woman is a great bane is this.' (Perseus)

Like D. Kovacs, the Perseus translator, I take it to mean 'it is clear that woman is a great evil', for $\dot{\omega} \varsigma$ is both a complementizer and a wh-term meaning how. Moreover, I know of no example of $\delta \tilde{\eta} \lambda$ ov with oĩoc, ö $\sigma o \varsigma$ or

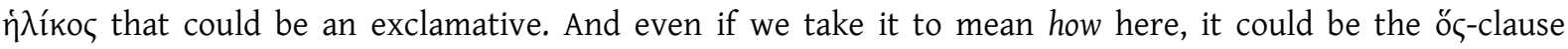
denoting the true answer to a question $\pi \tilde{\omega} \zeta$; 'how ?' and not an exclamative, $\dot{\omega} \varsigma$ being ambiguous like the English how (section 4.2 provides further syntactic clues that help disambiguate $\dot{\omega} \varsigma$ embedded exclamatives and interrogatives, such as the prolepsis).

${ }^{18}$ This remark was already in Elliott (1974:239): "[given that] exclamatory complements cannot occur at all with non-factives, (...) it really makes sense to speak of exclamatory complements as being factives."
} 
proposes that exclamatives do not denote propositions but facts, a proposal which I will not discuss in detail here.

The second consequence is that clauses that denote true answers to questions and exclamatives do not have the same distribution. To put it otherwise, exclamatives are reducible neither to interrogatives (something we already knew), nor to true answers. The criterion for question embedding is veridicality ${ }^{19}$ (Égré 2008, Faure 2010). On the other hand, exclamatives, being presupposed, require factivity and do not settle for veridicality.

\subsection{Wrap up}

In this section, I have come back to the long-standing debate on the presupposed character of exclamatives. I discussed it first on English data and highlighted the fuzziness of many tests. The best proof turned out to be Abels' test with respect to plugs for presupposition. Exclamatives are sensitive to plugs along with run-of-the-mill presuppositions. Then, I turned to CG data and built on what we learnt from the wh-morpheme $h$-in section 2.2 and on the exact correspondence between direct and embedded exclamatives to draw conclusions. Exclamatives are limited to factive predicates, contrary to embedded interrogatives that denote the true answer to a question, which require only veridicality. The conclusion is that wh-exclamatives are, both in English and CG, presupposed propositions. Now the question arises as to what a sentence made of a presupposed proposition contributes to the conversation, i.e. what the exclamative speech act is.

\section{Focus: What we learn from syntax}

In the previous section we saw that wh-exclamatives denote presupposed propositions, but also that this presupposition is particular in that it is made of two parts: the proposition from which the element denoted by the wh-term has been abstracted and the wh-term itself headed by the morpheme $h$ - The wh-term leaves a part of the proposition unexpressed: the amount, the degree to which the property is surprising and even the property itself with oíos. This is surprising under the view that the whole content is presupposed and then known. In this section, we shall focus on this point and on what more the wh-term has to tell us. Once again, exclamatives will be compared to ö $\zeta$-clauses denoting the true answer to a question, but this time on the syntactic side. We shall see that the wh-term lands in a topic-like position in the case of ös-clauses, but in a focus-like position in the case of exclamatives and interrogatives. We explain to what extent this mismatch between ö clauses and exclamatives raises the exclamative effect.

\footnotetext{
${ }^{19}$ This does not explain why interrogatives are not embedded under emotive factive predicates, for factive predicates are a subset of veridical predicates (recall the definition of veridical operator from (20)). Faure 2010 argues that, along with veridicality, assertivity is a required feature to embed interrogatives, a feature that emotive factives do not possess.
} 


\subsection{The left periphery of the CG clause}

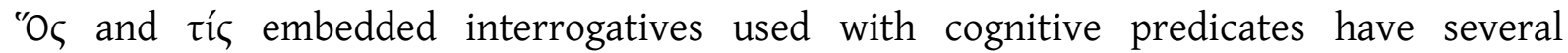
differences. One of them is particularly interesting: the peculiar phenomenon of the prolepsis. In a sentence with a completive, the NP that should be the subject of the verb of the embedded clause is placed in the matrix and bears the case assigned by the matrix verb to its object ${ }^{20}$. Thus, in (55), the subject of the embedded verb Ex$^{\prime} \times 01$ is the king. It is represented in the matrix clause by aủ óv, a pronoun in the accusative case that does not play any semantic role with respect to the matrix verb. It seems only to be an anticipation of the subject of the embedded clause, a kind of topicalization. Panhuis 1984 has shown that the NP in the prolepsis is always topical.

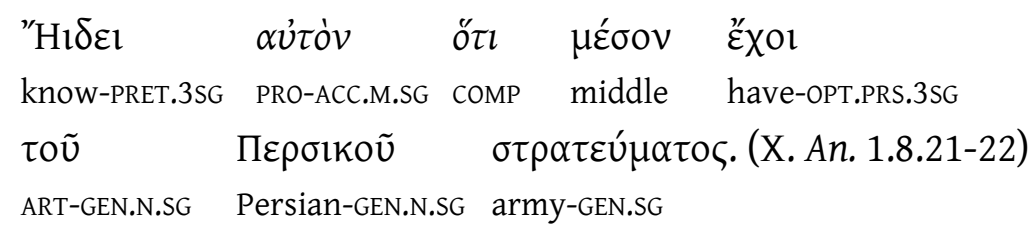

'He knew that he (the King) held the centre of the Persian army.'

Tí́s-, but not ö -clauses accept this phenomenon (56).

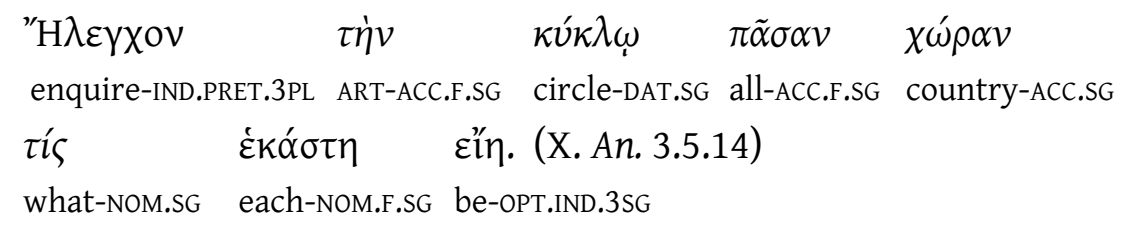

'(The generals) enquired about each district of all the surrounding country.'

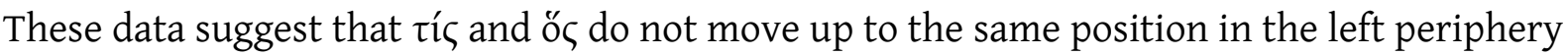
of the clause. As with many languages, the left end of the clause in $C G$ is devoted to discourse functions. In a non generative, non transformational framework, Matić 2003 proposed a very fine-grained scheme of the Greek clause word order. I give the narrow focus informational structure under (57) as modified in Bertrand 2009.

$\begin{array}{lll}\text { [Topic] } & \text { [Topic] [Topic] [Focal material] [Verb] [Topic] [Rest of the clause] } \\ \text { Frame } & \text { Frame Continuous } & \text { Continuous } \\ \text { contrastive-exclusive } & & \end{array}$

\footnotetext{
${ }^{20}$ Actually, there is another type of topicalization where the topicalized NP bears a case assigned in the embedded clause (see E. Ba. 173-174). In this case, the topicalized XP is not necessarily the subject of the embedded verb; it is even not necessarily an NP. I will not go into detail here. It is sufficient for my point to know whether a topicalization, whatever form it takes, is possible or not.
} 
We note that $C G$ has several positions for topics to the right of which there is a position for focus. Interestingly, Matić and Bertrand show that this structure is embeddable and recursive and that each clause has its own structure. The study of the prolepsis suggests

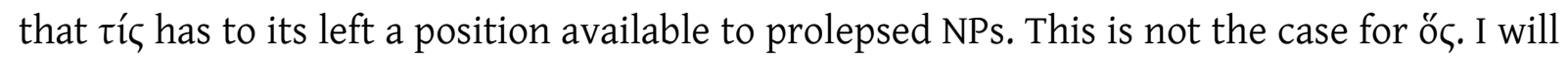
claim that this is due to the fact that ó $\zeta$ is at the leftmost edge of the clause. This means that

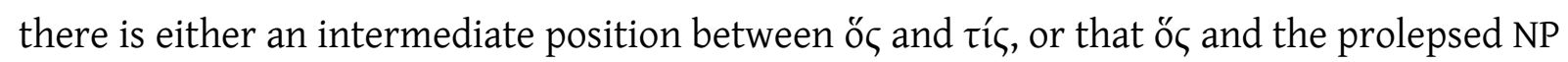
occupy the same position. Be that as it may, if we map these results onto the structure (57), ö and the prolepsed NP occupy a high topic-like position, while tí soccupies either a lower topic or the focus position. I shall argue that it is the focus position.

It has been pointed out that wh-interrogative terms and focus have many features in common. As a matter of fact, the interrogative term determines what will be the focus of the answer. In (58), who determines and constrains the informational structure of the answer: the subject of came must be focused. That is why B is a felicitous answer to A, but not B' where the verb is focus.
A: Who came?
B: $[\text { Bill }]_{\mathrm{F}}$ came.
B': \#Bill $[\text { came }]_{\mathrm{F}}$.

We end up with the following mapping:

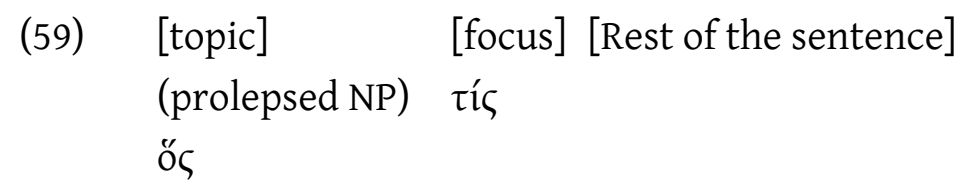

This is confirmed by the interpretational properties of the terms. We learnt from section 2.2 that ö $\varsigma$ is identificational. It is not surprising that it moves up to the specifier of a topic position, typically occupied by presupposed material, to check its identificational feature. On the other hand, $\tau$ í is non identificational. It moves up to the focus position typically devoted to new/unknown material, to check its non identificational feature. The topic head can be realized as a veridical/factive complementizer ö $\tau$ (de Boel 1980), as in (55) where the prolepsed NP is in its specifier. This presentation is rather sketchy ${ }^{21}$, but is sufficient to understand the remainder of the proof.

\subsection{Wh-exclamatives and the left periphery}

If we now turn back to the exclamatives, an interesting fact appears. Though headed by the wh-morpheme $h$-, the exclamatives accept the prolepsis. In (30), the pronoun $\dot{\eta} \mu \tilde{\alpha} \varsigma$ is coreferent with the subject of the embedded clause, but is placed in the matrix, where it

\footnotetext{
${ }^{21}$ The reader is referred to Faure 2010 for further development.
} 
receives the accusative case from ó $\rho \tilde{a}$ s (see also (D. 9.61)). Nevertheless it does not receive any semantic role from it. We are then in the same situation as in (55) and (56). This phenomenon is widely attested. This suggests that the exclamative term is in the same

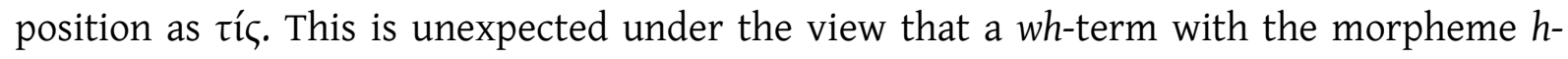
should move to the highest position to check its identificational feature. Consequently, we are left with an identificational expression in a non identificational (focus) position.

\subsection{Wrap up}

To sum up this section, I have showed that the left periphery of the CG clause is made of the articulation of (at least) two phrases, projections of two heads. These heads are underspecified and can host cognate material. The leftmost is identificational. It hosts topic expressions, veridical and factive complementizers and ö $\varsigma$-phrases. The rightmost is non

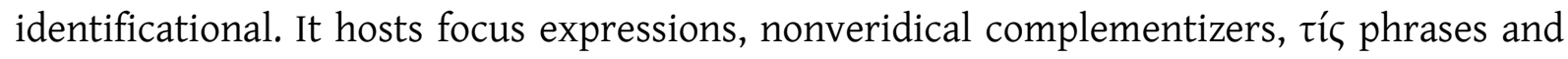
exclamatives phrases.

Interestingly, this mapping carries over to direct exclamatives. In (60) the NP o $\kappa \varepsilon \rho \alpha \mu \omega ́ v$ 'the bowl' is topicalized and precedes ö $\sigma \circ \varsigma^{22}$ which is in the lower position of the left periphery. Note that it cannot be in situ because all wh-exclamative terms move up to the left periphery in $C G$.

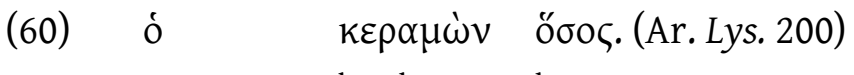

ART-NOM.M.SG bowl-NOM.SG how.muc-NOM.M.SG

'What a splendid bowl it is!'

If my syntactic account is correct, this means that wh-exclamatives are presupposed propositions with a focused wh-term. Note that there is a priori no contradiction between presupposition and focus. Run-of-the-mill presupposed expressions, such as definite NPs, can be focused. This is the case in (61).
A: Who came yesterday?
B: $[\text { Your brother }]_{\mathrm{F}}$ came yesterday.

Importantly, the association put forward here between non identification and focus is in line with an informational conception of focus ${ }^{23}$ and not with a contrastive conception of focus. However Rizzi 1997 associated the focus position in the left periphery with contrastive focus, the informational focus remaining in situ. In our view both types of focus are both informational and contrastive. The narrow focus position in the scheme of the CG clause (57) is an informational focus that can, moreover, be contrastive (Bertrand 2009).

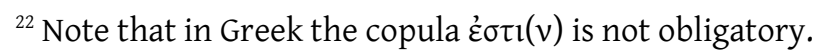

${ }^{23}$ Focus seen as what the sentence contributes to the conversation.
} 
This is in line with Schwarzschild 1999 conception of focus as related to givenness. Eventually the two notions merge (see section 5.4). The informational side of focus is useful to account for unexpectedness. The contrastive side of focus will prove useful in the next section. A well-known effect of focus is that it raises a set of alternative values. In the case of exclamatives, these alternatives belong to a definite, ordered scale. They were more expected than the actual value. This is the point under examination in the next section.

\section{Scalarity, degree, widening and unexpectedness}

So far, we have learned that CG wh-exclamatives are headed by degree terms, that they denote presupposed propositions and that their wh-term is in a focus position. In the present section I tie together these three features, showing that they are interdependent. The function of the focus is to open up the potential scale involved in the degree term, extending it to the surprising element. Thus I build on Zanuttini \& Portner's 2003 notion of widening, but I explain it in a complete different way.

\subsection{The focus effect}

An effect of focus is to open up a set of alternative propositions identifiable from the topical part of the sentence. It is the focus semantic value (Rooth 1992). For example the focus semantic value of (62) is the set of propositions where another (human) individual loves Arlequin (63) ${ }^{24}$.

(62) $\quad[\text { Silvia }]_{\mathrm{F}}$ loves Arlequin.

(63) $\left[\left[[\text { Silvia }]_{\mathrm{F}} \text { loves Arlequin }\right]\right]^{\mathrm{f}}=\{$ love $(\mathrm{x}, \mathrm{a}) \mid \mathrm{x} \in \mathrm{E}\}$, where $\mathrm{E}$ is the domain of individuals

(64) $\left[[\text { [Silvia }]_{\mathrm{F}}\right.$ loves Arlequin $\left.]\right]^{\circ}=$ love $(\mathrm{s}, \mathrm{a})$

In a declarative sentence the focus semantic value exists apart from the ordinary semantic value of the sentence (in this case (64)). This is not the case in an interrogative sentence, at least in some theories of questions. For example Hamblin 1973 takes a question to denote the set of the possible answers to the question, e.g. (66) for (65). The meaning of a whinterrogative sentence is just the focus semantic value of its answers (Rooth 1992). This is not surprising, given that the wh-term stands for what is focused in the declarative sentence that constitutes the answer.

(65) Who loves Arlequin?

(66) $\left[[\text { Who loves Arlequin?] }]^{\circ}=\left[\left[[\text { Silvia }]_{\mathrm{F}} \text { loves Arlequin }\right]\right]^{\mathrm{f}}\right.$

\footnotetext{
${ }^{24}$ In the formalization, I shall ignore the intensional part.
} 


\subsection{Degree and scalarity}

What about wh-exclamatives? Wh-exclamatives do have a focused term: the wh-term, but they do not denote a set of propositions. They denote propositions (they are embedded under propositional attitude verbs). This means that their meaning is not the meaning of the focus semantic value. But what is the meaning of the ordinary semantic value of an exclamative? In (3), the wh-term is oĩov. Its focus semantic value cannot be $(67)^{25}$ because of the ban on individual interpretation of wh-exclamatives (see section 2.1).

$$
[[\text { oĩov عippó } \sigma \alpha \sigma \theta \varepsilon]]^{\mathrm{f}}=\{\mathrm{do}(\mathrm{you}, \mathrm{x}) \mid \mathrm{x} \in \mathrm{E}\} \text {, where } \mathrm{E} \text { is the domain of individuals }
$$

We saw in section 2.1 that wh-exclamatives have only a degree interpretation. This means that one exclaims only on the degree attained by a property and not on the property itself or on the individual bearing the property. We also saw that the morpheme-ol- stands for a gradable property that is contextually evaluated. Gradable properties are taken, at least since Creswell, to include a degree variable. Creswell took adjectives like tall to be functions from properties to degree relation, i.e. $<<e, t>,<e,<e, t>>>$, for he treated degrees as other individuals and adjectives as having as basic meaning their attributive meaning. If degrees are considered as specific entities in the ontology (let us note them $d$ ), $<<e, t>,<e,<e, t>>>$ writes as $<<e, t>,<\mathrm{d},<\mathrm{e}, \mathrm{t}>>>$. Here we will take as basic meaning for gradable adjectives, the predicative meaning of adjective, much like Heim 2000, and tall will be for us $<\mathrm{d},<\mathrm{e}, \mathrm{t}>>$, a function from degrees to properties: $[[$ tall $]]=\lambda d_{d} \cdot \lambda x_{e} \cdot \operatorname{tall}(x, d)$ (meaning $x$ is tall to the degree $d$ ). Note that, along with Heim 2000, we assume that being tall to the degree $d$ means being tall to the degree $d$ and all lesser degrees on the tallness scale. -ot- stands for a gradable predicate variable, functioning like a pronoun, i.e. whose sense is retrieved contextually. Its meaning is then $(68)^{26}$.

$$
[[-o l-]]=\lambda d_{d} \cdot \lambda x_{e} \cdot-o l-(x, d)
$$

Along with degree interpretation, the second ingredient of exclamation is unexpectedness on which I concur with Rett $(2008,2009)^{27}$. The degree attained by the property is above both the relevant standard and the speaker's expectations so that it provokes her exclamation. It seems that in a scenario where you expected Robert to be 5 feet tall and where he is actually 5.5 feet tall, it is not felicitous to utter (69).

\footnotetext{
${ }^{25}$ For simplicity's sake, I ignore part of the proposition and the tense.

${ }^{26}$ Recall from section 2.1 that in h-ol-ov, -ov is nothing but the case morphology, which I ignore in the derivation.

${ }^{27}$ A feature noted a long time ago, e.g. in Elliott (1974:242) "the function of exclamations is clearly to talk about adnormal or unexpected situations". See also Michaelis \& Lambrecht 1996.
} 
(69) How tall Robert is!

(70) A: You know what? Rosalie made five cakes for the party.

B: What a nice person she is!

This means that to exclaim, the degree of the property does not only need to be unexpected, but also to be above a relevant standard. On the other hand, in a scenario where you expected Robert to be 6.5 feet tall, you cannot utter (69), unless your evaluation of what 6.5 feet tall would be like were under what it actually is. On the contrary, you can utter (69), if Robert is in fact 7 feet tall, i.e. above both the relevant standard and your expectations. In this last case, we retrieve unexpectedness. Similarly, exclamatives especially arise in contexts where the speaker has just been given a new piece of information that she did not expect. This kind of situations triggers exclamations such as in the short dialogue (70). Rett refers to this property to be above a standard as evaluativity, also used in positive adjectives. It is encoded through an operator she dubs $\mathrm{EVAL}^{28}$. (71) gives the meaning of this operator, where $s$ is a pragmatic variable, left unbound in the semantics, that returns the correct threshold for the gradable property $\mathrm{P}$.

$$
[[E V A L]]=\lambda P_{<d,<e, t>} \cdot \lambda d_{d} \cdot \lambda x_{e} \cdot\left[P(x, d) \wedge d>s_{P}\right]
$$

The role of the identifying morpheme $h$ - is to say that the degree $d$ of the property is known. Importantly, it is not the whole scale up to $d$ that triggers the exclamation, but only the maximum degree $d$ attained by the property. $h$ - binds only this highest degree. To put it otherwise, $h$ - functions as a maximality operator with, in addition, the information that the degree is known.

As an approximation, I will treat $h$ - as a definite article, but polymorphic and binding here a degree as illustrated in (72). As with the definite article, the formula does not incorporate the presuppositional part of the meaning. Recall that having a property to a degree $d$ is having a property to the degree $d$ and all lesser degrees. (72) says that $h$ - binds the degree $d$ such that all the other degrees to which $x$ possesses the property $\mathrm{P}$ are equal to or lower to $d$, i.e. $h$ - binds the maximal degree of the property as possessed by $x$. This binding does not intervene at the end of the derivation but inside the wh-phrase.

$$
[[h-]]=\lambda \mathrm{P}_{<\mathrm{d},<e, t>>} \cdot \lambda \mathrm{Q}_{<e, t>} \cdot \lambda \mathrm{x}_{\mathrm{e}} \cdot \exists \mathrm{d}_{\mathrm{d}}\left[\mathrm{P}(\mathrm{x}, \mathrm{d}) \wedge \forall \mathrm{d}_{\mathrm{d}}^{\prime}\left[\mathrm{P}\left(\mathrm{x}, \mathrm{d}^{\prime}\right) \rightarrow\left(\mathrm{d}^{\prime} \leq \mathrm{d}\right)\right] \wedge \mathrm{Q}(\mathrm{x})\right]
$$

\footnotetext{
${ }^{28}$ In her thesis (2008:chapter 3), she discusses the advantages of this operator over Kennedy's 2007 POS.
} 
(73) proposes a derivation of $(3)^{29}$ and gives its semantic value (see above, section 5.1). It says that there is a maximum degree to which $x$ possesses the property -ol- and that this degree exceeds the standard. What the formula does not incorporate is that this maximum degree is known to the speaker ${ }^{30}$ (the effect of the morpheme $h-$ ). But that does not suffice. What triggers the exclamative effect is the association between this known degree and the fact that it is focused as shown in its focus semantic value (74), i.e. the fact that this maximum degree is compared to other degrees of the same property. Exclamatives cannot be accounted for if these two levels are not taken into account. Otherwise the meaning of (3) would not be different from "you did a thing that has the property -ol- to a (maximum) degree that I know".

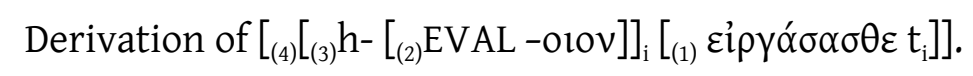

(1) $\left[\left[\varepsilon i p \gamma \alpha ́ \sigma \alpha \sigma \sigma \theta \varepsilon \mathrm{t}_{\mathrm{i}}\right]\right]=\lambda \mathrm{x}_{\mathrm{e}} \cdot \mathrm{do}(\mathrm{you}, \mathrm{x})$

(2) $[[E V A L-o l o v]]=\lambda d_{d} \cdot \lambda x_{e} \cdot\left[-o t-(x, d) \wedge d>s_{-o l}\right]$

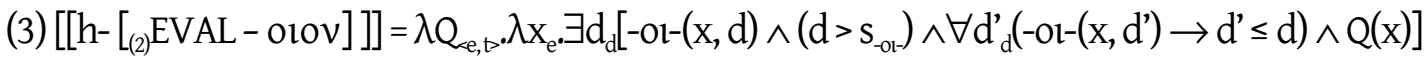

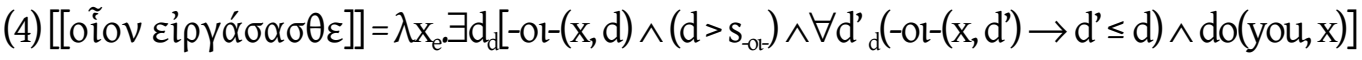

$\hookrightarrow_{\text {existential closure }} \exists \mathrm{x}_{\mathrm{e}}, \exists \mathrm{d}_{\mathrm{d}}\left[-\mathrm{ol}-(\mathrm{x}, \mathrm{d}) \wedge\left(\mathrm{d}>\mathrm{s}_{\text {-ot }}\right) \wedge \forall \mathrm{d}_{\mathrm{d}}^{\prime}\left(-\mathrm{ol}-\left(\mathrm{x}, \mathrm{d}^{\prime}\right) \rightarrow \mathrm{d}^{\prime} \leq \mathrm{d}\right) \wedge \mathrm{do}(\mathrm{you}, \mathrm{x})\right]$

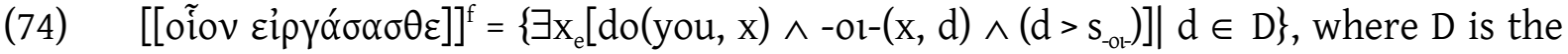
domain of degrees

\subsection{Exclamative focus semantic value}

Exclamatives denote propositions. Their ordinary semantic value and their focus semantic value are not equivalent, a crucial difference with interrogatives. As the focus is on the degree variable, the set of propositions that constitute the focus semantic value have the specific property to be both ordered and oriented. This was not the case for (62) where the alternative set is made of, say, \{Silvia loves Arlequin; Lisette loves Arlequin; Araminte loves Arlequin\}. This means that the exclamative fixes the degree to the uppermost degree available on the scale.

This opens up the possibility of widening, called for by Zanuttini \& Portner 2003 and intuitively attractive. They propose an account of the Paduan wh-exclamatives in (75).

\footnotetext{
${ }^{29}$ In order to keep things simple, I have not related the exclamative to the speaker as I should have. That would give:

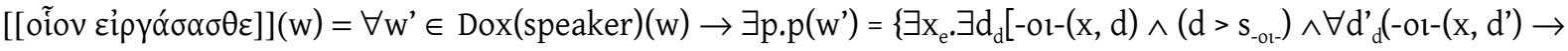
$\left.\mathrm{d}^{\prime} \leq \mathrm{d}\right) \wedge$ do $($ you, $\left.\mathrm{x})\right\}$

${ }^{30}$ Note that this is not trivial for I can know that $x$ has the property P without knowing to what degree.
} 
Che roba che 1 magna!

What stuff that he eats

'The things he eats!'

According to them, exclamatives are sets of propositions, like interrogatives, and the difference between the two types of speech acts resides in the factivity of exclamatives and in the pragmatics. (75) denotes the set of propositions where the wh-phrase is replaced for example by peppers. They present the set in the increasing order of spiciness: he eats poblanos; he eats serranos; he eats jalapeños\}. To utter (75), the speaker must notice that the eater also eats a more spicy pepper, say, habanero. Therefore the set widens to the eats poblanos; he eats serranos; he eats jalapeños; he eats habaneros\}.

In my account of CG wh-exclamatives, this is not possible. The exclamation always bears on a gradable expression. The food is not something gradable (except in quantity). The propositions vary according to individuals and not to elements belonging to a scale (Kennedy 2007). The set denoted by the exclamative would rather be a set of propositions varying according to the degree attained by a contextual property, say, spiciness: \{he eats something spicy; he eats something very spicy; he eats something enormously spicy\}. It happens that the strength of the spiciness of the peppers they propose is different for each pepper and that each pepper matches a proposition of this set. But even in that case, their set is not naturally ordered and oriented as the degrees of a gradable property are. This predicts that a widening could intervene not at the uppermost end of the scale but, say, in the middle, between poblanos and serranos, a non-desirable result, for (75) would become infelicitous in this context.

In my view, the widening can be seen as a side effect of the application of the focus on a gradable property. This has the advantage to provide an ordered scale of propositions that is widened by a proposition where the property has (at least) one degree more. As exclamatives are not sets of propositions, but propositions, this means that the ordinary semantic value of an exclamative is the proposition that widens the focus semantic value of the clause and not the entire set.

\subsection{Wrap up}

In this section we saw how the focus feature of CG wh-exclamatives combines with the necessary presence of a gradable property. First, the speaker's expectations have been disappointed. She has expectations or prejudices on several points. She may exclaim only on one of these points. Second, to be disappointed, the expectations must have alternatives. These alternatives are not free, they necessarily belong to an ordered scale. Scales are a feature of gradable properties. That is why the speaker can only exclaim on gradable properties (or on quantities). Third, for the speaker to be able to exclaim, the alternatives must be activated. The fact that the gradable property is in the focus activates the 
alternatives. From an informational point of view, the speaker has been given a piece of information that exceeded her expectations. By uttering an exclamation, she shows that she is reluctant to add it to the common ground, which is correlated to the fact that she keeps in mind the alternatives. The double nature of focus (informational and contrastive) is borne out.

\section{Concluding remarks}

CG wh-exclamatives show features that have been for a long while recognized for exclamatives across languages. Here is what Michaelis \& Lambrecht proposed in their 1996 paper:

- Presupposed open proposition.

- Scalar extent.

- Assertion of affective stance: expectation contravention.

- Identifiability of described referent.

- Deixis.

CG exclamatives are special in that they present a specific wh-operator, the morpheme $h^{-}$, that encodes the identification, and in that the wh-phrase can be shown to be in a focus position. My account provides new arguments for why exclamatives and interrogatives do not have the same semantics. It ties together the different features of exclamatives and shows how they are interdependent: both the focus and the degree features derive from the unexpectedness. Focus and degrees are tied in the sense that the focus opens the degree scale. Being a presupposed proposition (the speaker knows what the exclamative denotes), the piece of information conveyed by the exclamative is the expressive and not the descriptive content. The exclamative displays the reluctance of the speaker to accept the content of the exclamative. Note that to account for CG exclamatives, we do not need a factivity operator or a specific illocutionary operator. The illocutionary force is the effect of the combination of presupposition, focus and degree.

\section{References}

Abels, Klaus. 2004. Why surprise-predicates do not embed polar interrogatives. Linguistische Arbeitsberichte 79: 203-221.

Abels, Klaus. 2010. Factivity in exclamatives is a presupposition. Studia Linguistica 64 (1): 141157.

Bertrand, Nicolas. 2009. Les pronoms postpositifs dans l'ordre des mots en Grec ancien. Lalies 29: 227-252.

Castroviejo, Elena. 2007. A degree-based account of wh-exclamatives in Catalan. In Estela Puig-Waldmüller (ed.), Proceedings of Sinn und Bedeutung 11, 134-149. Barcelona: Universität Pompeu Fabra. 
Chernilovskaya, Anna and Rick Nouwen. to appear. On wh-exclamatives and noteworthiness. In Maria Aloni et al. (ed.), Proceedings of the 18th Amsterdam Colloquium. Lecture Notes in Computer Science,

Cresswell, Max J. 1976. The semantics of degree. In Barbara Partee (ed.), Montague grammar, 261-292.

d'Avis, Franz J. 2001. Über >w-Exklamativsätze< im Deutschen. Tübingen: Niemeyer.

d'Avis, Franz J. 2002. On the interpretation of wh-clauses in exclamative environments. Theoretical Linguistics 28 (1): 5-32.

de Boel, Gunnar. 1980. Towards a Theory of the Meaning of Complementizers in Classical Attic. Lingua 52 (3-4): 285-304.

Égré, P. 2008. Question-Embedding and Factivity. Grazer Philosophische Studien 78 (1): 85-125.

Elliott, Dale E. 1974. Toward a grammar of exclamations. Foundations of Language 11 (2): 231246.

Eriksson, Olof. 1982. Il m'a dit ce qu'il pense : interrogative ou relative ? Revue Romane 17 (2): 3-20.

Faure, Richard. 2006. Factifs cognitifs, factifs émotifs, liage bas et accommodation locale. Verbum 28 (4): 415-431.

Faure, Richard. 2009. Are Some Indirect Interrogatives Free Relatives Used as Concealed Questions? In Katerina Chatzopoulou, Alexandra Ioannidou and Suwon Yoon (ed.), Proceedings of the International Conference of the 9th International Conference on Greek Linguistics (ICGL 9) (Chicago, 29 October 2009 - 31 October 2009), 154-164. Chicago: University of Chicago.

Faure, Richard. 2010. Les Subordonnées interrogatives dans la prose grecque classique : les questions constituantes. Ph.D. Dissertation, Université de Paris IV-Sorbonne, Paris.

von Fintel, Kai. 2004. Would you believe it? The king of France is back! (presuppositions and truth-value intuitions). In Marga Reimer and Anne Bezuidenhout (ed.), Descriptions and beyond, 315-341. Oxford: Oxford University Press.

Grimshaw, Jane B. 1979. Complement selection and the lexicon. Linguistic Inquiry 10: 279-326. Groenendijk, Jeroen and Martin Stokhof. 1984. Studies on the Semantics of Questions and the Pragmatics of Answers. Ph.D. Dissertation, Amsterdam University, Amsterdam.

Hamblin, Charles L. 1973. Questions in Montague English. Foundations of Language 10: 41-53.

Heim, Irene. 2000. Degree operators and scope. In Brendan Jackson and Tanya Matthews (ed.), SALT 10, 40-64. Ithaca, NY: Cornell University.

Karttunen, Lauri. 1973. Presuppositions of compound sentences. Linguistic Inquiry 4: 169-193. Karttunen, Lauri. 1977. Syntax and Semantics of Questions. Linguistics and Philosophy 1 (1): 344.

Kennedy, Chris. 2007. Vagueness and grammar: The semantics of relative and absolute gradable adjectives. Linguistics and philosophy 30 (1): 1-45. 
Kiparsky, Paul and Carol Kiparsky. 1970. Fact. In M. Bierwisch and K. Heidolph (ed.), Progress in linguistics, 143-173. La Haye: Mouton.

Matić, Dejan. 2003. Topic, focus, and discourse structure : Ancient Greek Word Order. Studies in Language 27 (3): 573-633.

Michaelis, Laura A. and Knud Lambrecht. 1996. The exclamative sentence type in English. Conceptual Structure, discourse and language 375-389.

Milner, Jean-Claude. 1978. De la syntaxe à l'interprétation. Paris: Le Seuil.

Panhuis, Dirk. 1984. Prolepsis in Greek as a Discourse Strategy. Glotta 62 (1-2): 26-39.

Potts, Christopher. 2005. The Logic of Conventional Implicatures. Oxford: Oxford University Press.

Rett, Jessica. 2008. Degree modification in natural language. Ph.D. Dissertation, Rutgers University, New Brunswick.

Rett, Jessica. 2009. A degree account of exclamatives. In Tova Friedman and Satoshi Ito (ed.), Semantics and Linguistic Theory 18, 601-618. Amherst: UMass.

Rett, Jessica. 2011. Exclamatives, degrees and speech acts. Linguistics and Philosophy 34 (5): 411-442.

Rizzi, Luigi. 1997. The fine structure of the left periphery. In Liliane Haegeman (ed.), Elements of grammar, 281-337. Dordrecht: Kluwer.

Rooth, Mats. 1992. A theory of focus interpretation. Natural Language Semantics 1 (1): 75-116.

Saebø, Kjell Johan. 2011. Appositives in Modal Contexts. In Reich Ingo, Horch Eva and Pauly Dennis (ed.), Proceedings of Sinn und Bedeutung 15, 79-100. Saarbrücken: Universaar Saarland University Press.

Schwarzschild, Roger. 1999. Givenness, AvoidF and other constraints on the placement of accent*. Natural Language Semantics 7 (2): 141-177.

van der Sandt, Rob A. 1992. Presupposition projection as anaphora resolution. Journal of Semantics 9 (4): 333-377.

Zanuttini, Raphaela and Paul Portner. 2003. Exclamative clauses: At the syntax-semantics interface. Language 79 (1): 39-81.

Zwarts, Frans. 1995. Nonveridical contexts. Linguistic Analysis 25: 286-312. 